\title{
13 Y-chromosomal STRs in a Vietnamese population
}

\author{
Koji Dewa ${ }^{\mathrm{a}, \mathrm{b}}$, Nguyen Quang Tuyen ${ }^{\mathrm{c}}$, Steven Rand ${ }^{\mathrm{b}}$, \\ Carsten Hohoff ${ }^{\mathrm{b}}$, Bernd Brinkmann ${ }^{\mathrm{b}, *}$ \\ ${ }^{a}$ Department of Legal Medicine, Niigata University School of Medicine, Japan \\ ${ }^{\mathrm{b}}$ Institut für Rechtsmedizin Universität Tsklinikum Münster, \\ Röntgenstr. 23, D-48149 Münster, Germany \\ ${ }^{\mathrm{c}}$ Ministry of Interior Affairs, Hanoi, Viet Nam
}

\begin{abstract}
We present the frequency distributions of 13 Y-specific STR polymorphisms (DYS19, DXYS156, DYS385, DYS389 I and II, DYS390, DYS391, DYS392, DYS393, DYS437, DYS438, DYS439 and YCAII) and the frequency of the combination of these haplotypes in Vietnamese males.

(C) 2003 Elsevier Science B.V. All rights reserved.

Keywords: Y-linked STRs; Vietnamese; Haplotypes; Multiplex PCR

\section{Introduction}

One of the priorities of Y-chromosome STRs studies is to conduct population studies for the compilation of population databases which are as large as possible, include as many markers and from as many different populations as possible. In this study, we present frequency distributions of 13 Y-STR polymorphisms and frequencies of haplotypes in a Vietnamese population.
\end{abstract}

\section{Materials and methods}

DNA was extracted from saliva swabs of 119 unrelated Vietnamese males using the Chelex method. Amplification of the STRs was carried out in three multiplex reactions: DYS19, DYS389 I and II, DYS390, DYS393 (Y-multiplex I), DYS385, DYS437, DYS438,

\footnotetext{
${ }^{*}$ Corresponding author. Tel.: +49-251-83-55-160; fax: +49-251-83-55-158

E-mail address: brinkma@uni-muenster.de (B. Brinkmann).
} 
DYS439 (Y-multiplex II), DXYS156, DYS391, DYS392, YCAII and Amelogenin (Ymultiplex III). The primer sequences were those described earlier [1-3], For the Y-multiplex III, two primers were newly designed.

DXYS156

Forward primer: 5' GGTGAGAATCAATTCAAGAACTCA $3^{\prime}$ Reverse primer: 5' GCCTCCTTGGCTAGGTATATT 3'

YCAII Forward primer: 5' CAGGCATCCTTGTTTTTGCT $3^{\prime}$ Reverse primer: $5^{\prime}$ GTTCTTATTTAACCCACAATCAT $3^{\prime}$

The amplification protocol was as follows: $1 \mathrm{U}$ AmpliTaqGold, $0.1-3 \mu \mathrm{M}$ each primer, $200 \mu \mathrm{M}$ dNTPs, $25 \mu \mathrm{M} \mathrm{MgCl}_{2}, 3 \mu \mathrm{M}$ BSA, $1 \times$ PCR Gold Buffer, in a total volume of $25 \mu$. The forward primers were labeled with 6-FAM or HEX, respectively.
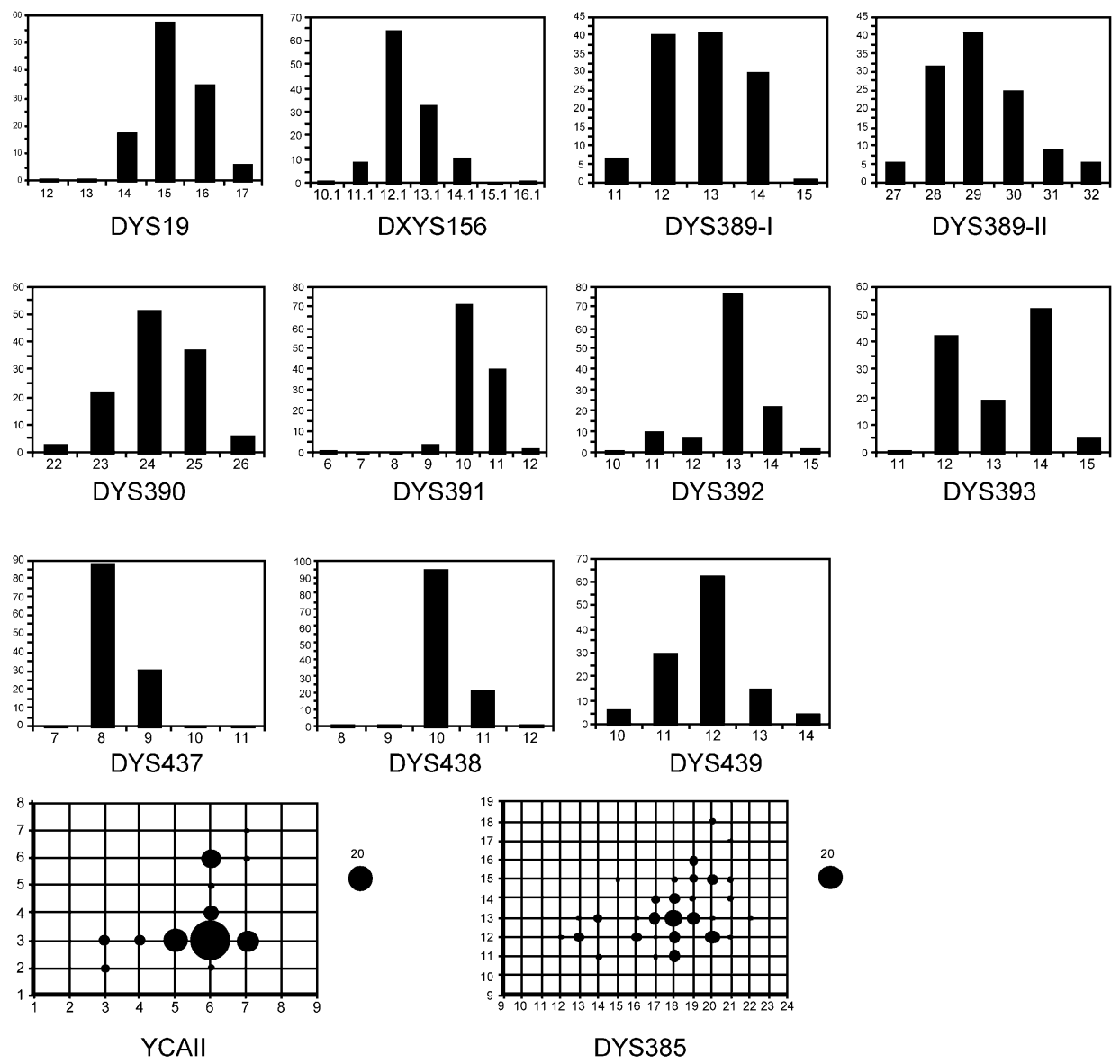

Fig. 1. Variation of 13 Y-STR loci in the Vietnamese population. 
The cycling conditions were as follows: for Y-multiplex I: preincubation $94{ }^{\circ} \mathrm{C}-10$ min, 31 cycles: $94{ }^{\circ} \mathrm{C}-1 \mathrm{~min}, 55^{\circ} \mathrm{C}-1 \min , 72{ }^{\circ} \mathrm{C}-1 \mathrm{~min}$, final extension $72{ }^{\circ} \mathrm{C}-30$ min; for Y-multiplex II: preincubation $94{ }^{\circ} \mathrm{C}-10$ min, 31 cycles: $94{ }^{\circ} \mathrm{C}-1 \mathrm{~min}, 60{ }^{\circ} \mathrm{C}$ $-1 \mathrm{~min}, 72{ }^{\circ} \mathrm{C}-1 \mathrm{~min}$, final extension $72{ }^{\circ} \mathrm{C}-30 \mathrm{~min}$; for Y-multiplex III: preincubation $94{ }^{\circ} \mathrm{C}-10 \mathrm{~min}, 32$ cycles: $94{ }^{\circ} \mathrm{C}-1 \mathrm{~min}, 55{ }^{\circ} \mathrm{C}-1 \mathrm{~min}, 72{ }^{\circ} \mathrm{C}-1$ min, final extension $72{ }^{\circ} \mathrm{C}-30 \mathrm{~min}$. Electrophoresis was carried out by capillary electrophoresis (ABI PRISM 310, Applied Biosystems) with sequenced allelic ladders.

\section{Results and discussion}

The allele frequencies are shown in Fig. 1. In 119 Vietnamese samples, 113 different haplotypes were observed, of which 107 haplotypes were unique and the others were shared by two persons. For an informative core set of 8 Y-linked STRs constantly updated in Europe (minimal haplotype DYS19, DYS385, DYS389 I and II, DYS390, DYS391, DYS392, DYS393), 107 different haplotypes were detected and further inclusion of YCAII (extended haplotype) yielded 108 different ones.

Comparing the haplotype data to other population data, we could find neither a match between Vietnamese and Syrian $(n=113)$ nor between Vietnamese and German $(n=268)$ data.

Interestingly, one of the Vietnamese haplotypes matched to an entry in the European Y-STR Database $(n=2322)$.

Diversities of the individual loci ranged from 0.33 (DYS438) to 0.95 (DYS385) and the haplotype diversity was 0.99 . For the extremely polymorphic DYS385, the allele $13 / 18$ was most commonly found in $11.7 \%$ of Vietnamese samples, whereas the allele $11 / 14$ was most common in the Germans (33.2\%, data not shown).

\section{Acknowledgements}

The authors wish to thank M. Schürenkamp and U. Sibbing (University of Münster, Germany).

\section{References}

[1] M. Kayser, A. Caglià, D. Corach, et al., Evaluation of Y-chromosomal STRs: a multicenter study, Int. J. Leg. Med. 110 (1997) 125-133.

[2] P. de Knijff, M. Kayser, A. Caglià, et al., Chromosome Y microsatellites: population genetic and evolutionary aspects, Int. J. Leg. Med. 110 (1997) 134-140.

[3] Q. Ayub, A. Mohyuddin, R. Qamar, et al., Identification and characterisation of novel human Y-chromosomal microsatellites from sequence database information, Nucleic Acids Res. 28 (2000) e8. 